\title{
Associations of early adulthood life transitions with changes in fast food intake: a latent trajectory analysis
}

Eleanor M. Winpenny ${ }^{1 *}$ (D), Megan R. Winkler ${ }^{2}$, Jan Stochl ${ }^{3,4}$, Esther M. F. van Sluijs ${ }^{1}$, Nicole Larson ${ }^{2}$ and Dianne Neumark-Sztainer ${ }^{2}$

\begin{abstract}
Background: Early adulthood is a period of rapid personal development when individuals experience major life transitions (e.g. leaving the parental home, leaving education, beginning employment, cohabitation and parenthood). Changes in social and physical environments associated with these transitions may influence development of health-related behaviours. Consumption of fast food is one behaviour associated with poor diet and long-term health outcomes. In this study we assess how frequency of fast food consumption changes across early adulthood, and how major life transitions are associated with changes in fast food intake.
\end{abstract}

Methods: Data were collected across four waves of the Project EAT study, from mean age $14.9(S D=1.6)$ to mean age 31.1 ( $S D=1.6)$ years. Participants reporting data at two or more waves were included $(n=2902)$. Participants reported past week frequency of eating food from a fast food restaurant and responded to questions on living arrangements, education and employment participation, and having children. To assess changes in fast food we developed a latent growth model incorporating an underlying trajectory of fast food intake, five life transitions, and time-invariant covariates.

Results: Mean fast food intake followed an underlying quadratic trajectory, increasing through adolescence to a maximum of 1.88 (SE 0.94) times/week and then decreasing again through early adulthood to 0.76 (SE 2.06) times/ week at wave 4. Beginning full-time employment and becoming a parent both contributed to increases in fast food intake, each resulting in an average increase in weekly fast food intake of $0.16(p<0.01)$ times/week. Analysis of changes between pairs of waves revealed stronger associations for these two transitions between waves 1-2 (mean age 14.9-19.4 years) than seen in later waves. Leaving the parental home and beginning cohabitation were associated with decreases in fast food intake of $-0.17(p=0.004)$ and $-0.16(p=0.007)$ times/week respectively, while leaving full-time education was not associated with any change.

Conclusions: The transitions of beginning full-time employment and becoming a parent were associated with increases in fast food intake. Public health policy or interventions designed to reduce fast food intake in young adults may benefit from particular focus on populations experiencing these transitions, to ameliorate their impact.

Keywords: Fast food, Young adult, Life transition, Diet, Education, Employment, Partner, Parenthood, Longitudinal

\footnotetext{
* Correspondence: ew470@cam.ac.uk

${ }^{1}$ MRC Epidemiology Unit, University of Cambridge, Cambridge, UK

Full list of author information is available at the end of the article
} 


\section{Background}

Early adulthood (age 18-30 years) is the life course stage when prevalence of overweight and obesity increases the fastest [1]. The poor quality diet often consumed at this age [2] is likely to contribute to this increase. Behaviours established during early adulthood, including obesityrelated behaviours such as dietary intake, eating behaviours and physical activity behaviours, may persist into later adulthood [3], influencing the risk of noncommunicable disease in later life $[4,5]$. Early adulthood has been identified as an important age for health behaviour interventions, which may be more successful at a time when habits are disrupted by lifestyle changes [6]. There is a need to build a better understanding of factors affecting changes in diet during early adulthood, and how this contributes to the establishment of longterm dietary behaviours to inform the development and targeting of diet interventions.

One negative aspect of people's dietary intake that has increased in recent decades is consumption of food from fast food restaurants $[7,8]$. In the U.S., the highest consumption of fast food is reported by young adults (aged $20-39$ ); $45 \%$ of this population subgroup reports consuming fast food on any given day [9]. In the UK, young adults (age 16-24 yrs) were also the age group reporting highest fast food consumption, with 54\% reporting eating in a fast food restaurant in the past month [10]. Frequent fast food consumption is associated with lower overall diet quality $[2,11]$, and longitudinal research has shown that higher frequency of fast food consumption in young adulthood is prospectively associated with increases in body weight and insulin resistance over the following 15 years [12].

Few studies have investigated longitudinal changes in fast food intake with age. Analysis of data from The National Longitudinal Study of Adolescent Health (Add Health), showed an increase in fast food consumption from age 16 (2.15 (SE 0.05) times per week) to age 21 (2.48 (SE 0.05) times per week) [13]. Similarly, previous analysis of the Project EAT (Eating and Activity in Teens and Young Adults) cohort has reported an initial increase in prevalence of high fast food intake (3 or more times per week) from adolescence (mean age 14.8 y (SD 1.6)) to early adulthood (mean age 19.4 y) with a maximum prevalence of $27.8 \%$ of males and $25.8 \%$ of females consuming fast food three or more times per week at this age, followed by subsequent decreases across time points in early adulthood (mean age $25.3 \mathrm{y}$ and $31.0 \mathrm{y}$ ) [14]. Little is known regarding what social and environmental factors might contribute to changes in fast food intake over this period [15].

Early adulthood is a period of rapid personal development [16], as well as a time when individuals experience major changes in their social and physical environments and financial resources, identified as determinants of health behaviour [17]. In particular, there are five major life transitions which are likely to occur in early adulthood: moving out of the parental home, leaving education, beginning employment, cohabitation with a significant other, and becoming a parent [18, 19]. Some of these transitions have previously been found to be associated with changes in adiposity and physical activity. For example, transitions from high school to college, and the transition to becoming a parent have been found to be associated with increases in body weight, and leaving high school is associated with decreases in physical activity $[20,21]$. However, there is little evidence of these transitions leading to changes in eating behaviours or dietary intake. A study of Norwegian data reports decreases in fruit and vegetable intake on leaving the parental home and increases in confectionery and sugarsweetened beverage intakes on leaving education [18]. A small number of studies suggest that consumption of fruit, vegetables and dairy may decrease across the transition from high school to college [21], but report little change in dietary intake in those becoming parents [20]. Building a better understanding of the processes and mechanisms that shape diet and eating behaviours during early adulthood will be crucial to inform how best to intervene to promote the establishment of healthy behaviours and a high quality diet that persists from early to later adulthood.

In this study we aimed to address the research question: "How are the life transitions of early adulthood associated with changes in fast food intake?". To address this question we: (1) described the prevalence and timing of the five life transitions in our population of US adolescents and young adults, (2) modelled the underlying trajectory of change in fast food intake with age across early adulthood, and (3) modelled associations between each life transition and change in fast food intake, accounting for the underlying trajectory, other life transitions, and time-invariant covariates.

\section{Methods}

\section{Participants}

Data for the current analysis were collected in Project EAT (Eating and Activity in Teens and Young Adults), a longitudinal study of weight-related health. In 19981999 (wave 1), a cross-sectional investigation of students at 31 public secondary schools in the metropolitan area of Minneapolis-St. Paul, Minnesota, U.S. was conducted. Public middle schools and high schools in the Minneapolis/St. Paul metropolitan area, serving socioeconomically and racially/ethnically diverse communities, were invited to participate in the study. Of 53 schools contacted, 31 agreed to take part. Participants aged 11 to 18 (mean age 14.9, $n=4746$ ) completed surveys during 
class time, and height and weight measurements were taken by trained research staff in a private area [22, 23].

Given growing interest in weight-related health, a decision was made to follow-up with participants who provided sufficient contact information $(n=3672)$ at 5 -year intervals. Follow-up assessments were completed by mail and online in 2003-04 (wave 2, $n=2516$ ), 2008-09 (wave 3, n=2287) and 2015-16 (wave 4, n=1830) as participants progressed through adolescence and early adulthood [24]. At each wave participants completed a survey of around 100 questions, focused on diet, eating behaviours and other weight-related behaviours. At the final follow-up, wave 4, invitations to complete the survey were mailed along with a two-dollar bill to all participants who had responded to at least one previous follow-up survey. Survey invitation letters provided the web address and a unique password for completing the online version of the survey. Non-responders received up to six reminders through a combination of U.S. mail, email, and text messages. The final two mailed reminders included paper copies of the survey and FFQ, and all mailings provided the option to complete the survey by phone. Reminder emails were additionally mailed to participants that did not complete the survey and FFQ after logging into the online version. Participants were mailed a financial incentive $(\$ 50)$ following survey completion. The University of Minnesota's Institutional Review Board Human Subjects Committee approved all protocols, with parental consent and participant assent obtained at wave 1 and participant consent obtained at each of the subsequent waves. In this study, given the focus on life transitions between waves of data collection, individuals were included in the analysis if they reported data at 2 or more waves of Project EAT $(n=2902)$, and therefore provided data that covered at least one period during which a transition may occur.

\section{Exposures}

To allow for longitudinal comparisons, each wave of the EAT study included identical measures of key constructs. We report the psychometric properties of measures using data collected for Wave 4. The estimates of item test-retest reliability, reported below, were determined in a subgroup of 103 participants who completed the Wave 4 survey twice within a period of one to 4 weeks. The EAT surveys included measures of each of the five major life transitions that was based on assessment of living arrangements, participation in education and employment, and having children. Below we describe the measures used to assess each transition and how these were used to create the exposure variable used in the analysis. In a small number of cases (less than $10 \%$ of the population for each exposure) individuals who had gone through a life transition returned to pre-transition state (e.g. they moved back into the parental home). As we were primarily interested in the first occurrence of a life transition, we coded any data points after the return to the pre-transition state as missing, thereby removing them from the analysis. For example, if a participant reported living with parents at wave 1 , not living with parents at wave 2 , but then reported living with parents again at wave 3 , the variable "leaving the parental home" would be coded as missing at wave 3 and wave 4 for that participant. This only applied to a small number of participants and did not contribute greatly to missing data.

Leaving the parental home was measured by asking participants about their current living arrangements at Waves 2-4. Participants were asked to select all that applied of nine options (e.g., "my parent(s)") in answering "During the past year, with whom did you live the majority of the time?". As this item was not asked when participants were under age 18, we assumed all participants were living with their parent(s) at Wave 1 and at Wave 2 if they were still a high school student. Based on the selection of "my parents" (Test-retest agreement = 97\%) from the list of provided response options, participants were categorized as 'living with parents' or 'not living with parents' at waves $2-4$. The transition variable of 'leaving the parental home' was positive the first time participants reported not living with parents.

Leaving full-time education was based on data about current educational status collected at waves 2, 3 and 4 in response to the question: "Which of the following best describes your student status (for the majority of the past year)?" (Test-retest agreement $=95 \%)$. Responses included type of education (e.g. community or technical college, four-year college) and whether education was full or part-time. Since Wave 1 surveys were administered in school classrooms, we assumed that all participants were attending full-time education at this time point. Graduate studies (reported at waves 3 and 4) was included under part-time education since no information was available as to whether graduate study was fulltime or part-time, and data from the U.S. Department of Education suggests that $64 \%$ of graduate students completed their studies as part-time students in 2015-16 [25]. Less than $8 \%$ of the sample reported graduate studies at Waves 3 and 4, so this assumption is not likely to strongly affect our results. The transition variable of 'leaving full-time education' was positive the first time that participants reported participation in part-time or no education.

Beginning full-time employment was based on data about current employment status, derived in response to the question: "How many hours a week do you work for pay?" (Test-retest $r=0.80$ ). Response options differed for 
those still in high-school compared to subsequent questionnaires. Those still in high-school only reported hours of work up to a maximum of ' 20 or more hours a week'; we categorised these individuals as participating in parttime work since they were still in full-time education. For those who had completed high-school, we categorised full time work as 30 or more hours per week [26]. The transition variable of 'beginning full-time employment' was positive the first wave that participants reported full-time work.

Beginning cohabitation with a significant other was based on responses to the current living situation measure that is described above. Participants who selected "my husband/wife" (Test-retest agreement $=93 \%$ ), "my partner of the opposite sex" (Test-retest agreement = 92\%), or "my partner of the same sex" (Test-retest agreement $=100 \%$ ) were categorized as cohabiting with a significant other. As above, since this question item was not asked when participants were under age 18, we assumed all individuals at wave 1 and those who were still high school students at wave 2 did not live with a partner. The transition variable of 'beginning cohabitation' was positive the first time that participants began to report living with a partner.

Becoming a parent was based on responses to survey questions that asked participants to report how many children they had at waves 2,3 , and 4 (Test-retest $r=$ 0.98). This question was not asked at wave 1 , and it was assumed that participants did not have any children at wave 1 , unless further detailed data on child age collected at wave 4 indicated that they would have already had a biological child at wave $1(n=10)$. 'Becoming a parent' was positive the first time that individuals moved from having no children to having one or more child at a subsequent wave.

\section{Outcomes}

Fast food consumption frequency was reported at each wave in response to the question: "In the past week, how often did you eat something from a fast food restaurant (like McDonald's, Burger King, etc.)?". Response categories were converted to a continuous scale of times per week: never [recoded to 0 times per week], 1-2 times [1.5], 3-4 times [3.5], 5-6 times [5.5], 7 times [7], more than 7 times [10], as done previously [27]. This measure was developed for the Project EAT study and is comparable to established measures used by other studies such as the National Longitudinal Study of Adolescent Health [13].

\section{Covariates}

We included baseline sociodemographic variables that may be associated with both life transitions and underlying changes in fast food intake as time-invariant covariates. These include age, gender, race/ethnicity, parental socio-economic status (SES) and health status $[9,15]$. Baseline age of the participant in years and months, and gender were reported at wave 1 . Race/ethnicity was also reported at wave 1 and collapsed to give two categories: (1) White (non-Hispanic) and (2) People of Colour. Parental SES was primarily determined from parental education, defined by the highest level of education achieved by either parent, as reported by the participants at Wave 1. This measure was complimented by additional variables on family eligibility for public assistance (yes, no, and do not know), eligibility for free or reduced-cost school meals (yes, no, and do not know), and maternal and paternal employment status (full-time, part-time, not working, and do not know), as described previously [28], to give a 5-level variable from 1 (low SES) to 5 (high SES). Overall health status was reported at waves 1 and 2 in response to the question "How would you describe your health?", with response options poor (1), fair (2), good (3) or excellent (4). In order to provide a longer-term measure of health rather than only a snapshot at the time the initial questionnaire was completed, responses were averaged across waves 1 and 2 to represent baseline health status.

\section{Statistical analysis}

Descriptive analyses were performed to evaluate sample population demographics and changes in fast food intake and occurrence of life transitions across the 4 waves. We tested for differences between the sample demographics of those included and excluded from our analysis (age, gender, race/ethnicity, parental SES and baseline health status) using linear regression and chi-squared tests. We calculated the phi coefficients of associations between pairs of transitions, to assess the likely influence of collinearity.

Latent growth curve models were used to test our research questions. Growth models were developed as a hierarchy of increasing complexity. First an unconditional growth model was estimated to examine overall growth trajectories and to test for individual variability in change over time. We tested the main effects of 5 time-invariant covariates: baseline age, gender, ethnicity, parental SES and baseline health status, including these in the model as predictors of the intercept, slope and quadratic slope of the growth curve (Fig. 1). Additional latent factors were then included to test for associations of each of the early adult life transitions with changes in fast food intake between pairs of waves, following Curran et al. [29], as shown in a path diagram in Fig. 1. Each of these latent factors (int2, int3 and int4) represents an additional intercept which is added to the growth curve at wave 2, 3 and 4 respectively. These additional intercepts are regressed onto the transition variables (T1-T5) 


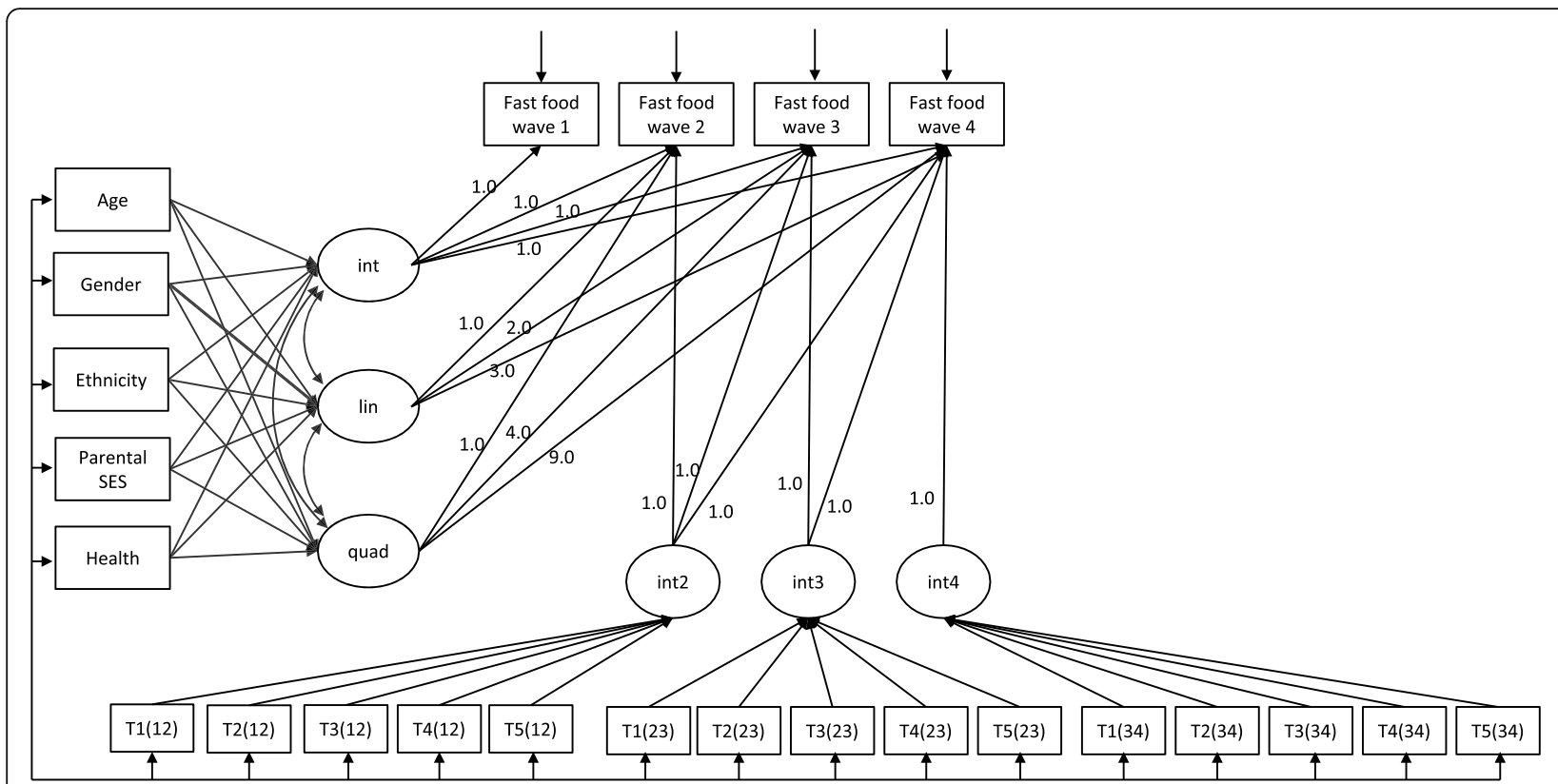

Path diagram of growth model showing latent growth factors, time-invariant covariates and time-varying exposures. Note: In this diagram boxes represent measured variables, while circles indicate latent variables. Int $=$ intercept, lin $=$ linear slope, quad $=$ quadratic slope; int 2 , int 3 and int 4 are additional intercepts at wave 2, 3 and 4 respectively. T1-T5 are life transitions, with T1(23) indicating a transition between waves 2 and 3. The numbers on each arrow represent the loadings of the growth factors on the observed variables

Fig. 1 Path diagram of growth model showing latent growth factors, time-invariant covariates and time-varying exposures

and their variance constrained to 0 such that the regression coefficients produced represent a step increase or decrease in fast food intake associated with each transition. For each transition we compare those who went through the transition with a reference category of those whose status did not change between consecutive waves: they did not transition, or stayed in the transitioned state between 2 waves. Since the additional intercept between waves is regressed on all transition variables, the associations of each of these transitions are mutually adjusted.

To examine the associations between fast food intake and life transitions, we developed two separate growth curve models: in the first model, 'Transitions across all waves', the association between the transition and the change in fast food intake was constrained to be the same across all waves, providing an overall indication of change in fast food intake associated with that transition, regardless of the timing of the transition during early adulthood. We then removed this constraint, to assess 'Transitions between pairs of waves', allowing the association between the transition and fast food intake to vary over time, to look at the effect of a transition occurring between each contiguous pair of waves.

Since adolescents were recruited through schools we also tested whether school-level intraclass correlation coefficients (ICCs) might suggest use of multilevel analysis to adjust for clustering by school. However, ICCs were low (ICC of 0.02 for baseline fast food intake and lower at subsequent waves), which, with an average cluster size of 94, suggests little impact of clustering on these analyses. Therefore, adjustment for school-level clustering was not included.

All models were estimated in Mplus (version 8.3) using the maximum likelihood estimator with robust standard errors (MLR), which is robust to non-normality in the dependent variable. Missing data were addressed using the full information maximum likelihood estimation, under the Missing at Random assumption, with variables related to attrition included as time-invariant covariates in the model. Model fit was assessed using a panel of fit indices: Akaike Information Criterion (AIC), Bayesian Information Criterion (BIC), Root Mean Square Error Of Approximation (RMSEA), Comparative Fit Index (CFI), Standardized Root Mean Square Residual (SRMR).

\section{Results}

\section{Sample characteristics}

Longitudinal data were available from participants from up to four waves of data collection, at mean ages 14.9 ( $\mathrm{SD}=1.6), 19.4(\mathrm{SD}=1.7), 25.3(\mathrm{SD}=1.6)$ and $31.1(\mathrm{SD}=$ 1.6) years. Participants $(n=2902)$ who provided data at two or more waves were included in the analysis, since two waves of data were required to allow a life event to be recorded between waves. Baseline descriptive data for the included sample are shown in 
Table 1. The analytical sample consisted of a greater proportion of participants who were female, nonHispanic White, and were of higher parental SES than the excluded sample.

\section{Prevalence and timing of life transitions in the study population}

Each of the five transitions were common within our population (Table 2), ranging from $87.1 \%$ of individuals leaving full-time education to $43.2 \%$ becoming a parent across all the waves of data available. Table 2 also reports the proportion of participants who experienced a transition between each pair of waves. For example, the highest proportion of participants $(32.4 \%)$ left the parental home between waves 1 and 2. The correlation between timing of transitions was low $(<0.3)$ for most pairs of transitions. The highest correlation being between leaving education and starting full-time work occurred between waves 1 and 2 and showed a phi coefficient of 0.47. Phi coefficients for associations between each pair of transitions are shown in Table S1 (see supplementary information).

\section{Trajectory of fast food intake with age}

We developed a growth model to capture changes in fast food intake with age and across transitions, across all four waves of data. We first tested model fit of the unconditional growth model with either a linear, quadratic or a non-linear model with estimated time scores, finding that model fit was best with an underlying quadratic model (see Table S2, supplementary information). Model fit further improved with the addition of covariates and additional latent intercepts associated with betweenwave transitions. The full model (Fig. 1) showed good model fit with $\mathrm{RMSEA}=0.015, \mathrm{CFI}=0.957, \mathrm{SRMR}=$

Table 1 Demographic characteristics of the included sample: participants in the Project EAT study with two or more waves of survey data $(n=2902)$

\begin{tabular}{ll}
\hline & Included sample \\
\hline Age at wave 1, mean (SD) & $14.9(1.6)$ \\
Gender: \% female (n) & $53.8(1561)$ \\
Race/ethnicity: \% non-Hispanic white, (n) & $59.8(1719)$ \\
Parental SES, \%, (n) & \\
1 (lowest) & $16.2(464)$ \\
2 & $17.1(491)$ \\
3 & $23.6(678)$ \\
4 & $26.9(771)$ \\
5 (highest) & $16.2(466)$ \\
Health status: \% good or excellent, (n) & $65.1(1869)$ \\
\hline
\end{tabular}

0.011. Based on this full model, we report an underlying growth curve with intercept 1.69 (SE 0.03), linear slope 0.33 (SE 0.06), and quadratic slope-0.14 (SE 0.02). Figure 2 shows the modelled trajectory of fast food intake over time, together with mean reported fast food intake at each age. This growth curve represents the mean trajectory of a population who do not go through any of the transitions. This trajectory shows that fast food intake increased through adolescence to a maximum of 1.88 (SE 0.94) times/week and then decreased again through early adulthood to 0.76 (SE 2.06) times/ week at wave 4 (Fig. 2). Associations between the growth trajectory and time-invariant covariates are shown in Table S3.

\section{Associations between life transitions and changes in fast food intake}

Associations with changes in fast food intake were observed for all life transitions except for leaving full-time education. Leaving the parental home and beginning cohabitation were both associated with decreases in fast food intake while beginning full-time employment and having a child were associated with increases in fast food intake (Table 3, model 1). When considered by wave, a number of transitions only show statistically significant associations with fast food intake between specific waves (Table 3, model 2). For example, the decrease in fast food intake associated with leaving the parental home reduced with age, while the decrease in fast food intake on beginning cohabitation increased with age. These time-specific effects should be interpreted with respect to the underlying growth curve (Fig. 2), and other ongoing transitions. For example, a decrease in fast food intake of -0.25 times per week on leaving the parental home between waves 1 and 2 is set against the underlying upward trend at this time, suggesting that, on average, leaving the parental home was associated with flattening the underlying increase in fast food seen over this period, rather than, on average, a decrease in intake.

\section{Discussion}

In this longitudinal analysis of young adults, we explored how fast food intake changed through early adulthood, and how five life transitions of early adulthood are associated with changes in fast food intake. Factors contributing to increases in fast food intake were beginning full-time employment and becoming a parent. The strongest association between these transitions and fast food intake was seen between waves 1 and 2 (mean age 15-19 years), when the effect of these transitions was in addition to an underlying increase of a similar magnitude over this period. Leaving the parental home and beginning cohabitation were associated with decreases in 
Table 2 Descriptive data on life transitions among participants in the Project EAT study with two or more waves of survey data $(n=$ 2902)

\begin{tabular}{|c|c|c|c|c|}
\hline & \multirow{2}{*}{$\begin{array}{l}\text { Across all } \\
\text { waves }\end{array}$} & \multicolumn{3}{|c|}{ Between pairs of waves } \\
\hline & & Waves 1-2 & Waves 2-3 & Waves 3-4 \\
\hline \multicolumn{5}{|l|}{ Leaving the parental home } \\
\hline Completes transition, \%(n) & $76.3(2214)$ & $32.4(940)$ & $29.7(863)$ & $14.2(411)$ \\
\hline No transition, \%(n) & $22.8(661)$ & $54.3(1576)$ & $37.3(1083)$ & $43.8(1271)$ \\
\hline Missing, \%(n) & $0.9(27)$ & $13.3(386)$ & $32.9(956)$ & $42.0(1220)$ \\
\hline \multicolumn{5}{|l|}{ Leaving full-time education } \\
\hline Completes transition, \%(n) & $87.1(2527)$ & $26.3(763)$ & $49.0(1423)$ & $11.8(341)$ \\
\hline No transition, \%(n) & $12.3(357)$ & $58.6(1700)$ & $27.2(789)$ & $47.9(1390)$ \\
\hline Missing, \%(n) & $0.6(18)$ & $15.1(439)$ & $23.8(690)$ & $40.4(1171)$ \\
\hline \multicolumn{5}{|c|}{ Beginning full-time employment } \\
\hline Completes transition, \%(n) & $74.7(2169)$ & $26.5(769)$ & $35.8(1038)$ & $12.5(362)$ \\
\hline No transition, \%(n) & $24.0(697)$ & $58.6(1701)$ & $34.8(1010)$ & $41.7(1210)$ \\
\hline Missing, \%(n) & $1.2(36)$ & $14.9(432)$ & $29.4(854)$ & $45.8(1330)$ \\
\hline \multicolumn{5}{|l|}{ Beginning cohabitation } \\
\hline Completes transition, \%(n) & $59.9(1739)$ & $10.5(305)$ & $31.9(925)$ & $17.5(509)$ \\
\hline No transition, \%(n) & $39.5(1145)$ & $76.2(2211)$ & $39.8(1155)$ & $40.3(1169)$ \\
\hline Missing, \%(n) & $0.6(18)$ & $13.3(386)$ & $28.3(822)$ & $42.2(1224)$ \\
\hline \multicolumn{5}{|l|}{ Becoming a parent } \\
\hline Completes transition, \%(n) & $43.2(1254)$ & $9.7(281)$ & $15.6(454)$ & 17.9 (519) \\
\hline No transition, \%(n) & $56.1(1627)$ & $75.7(2197)$ & $61.5(1784)$ & $41.5(1205)$ \\
\hline Missing, \%(n) & $0.7(21)$ & $14.6(424)$ & $22.9(664)$ & $40.6(1178)$ \\
\hline
\end{tabular}

'No transition' includes both those who have not yet transitioned or who have already completed a transition, i.e. those who show no change in status between 2 waves. Mean age at each wave: wave 1: 14.9y $(S D=1.6)$, wave 2: 19.4y $(S D=1.7)$, wave 3: $25.3 y(S D=1.6)$ and wave 4: 31.1y $(S D=1.6)$

fast food intake, while leaving full-time education was not associated with a change in fast food consumption. These findings suggests that those starting employment and starting a family early in life are at the highest risk for increases in fast food intake, and public health policy or interventions may benefit from focus on these groups.

\section{Comparison with previous research}

The frequency of fast food intake seen in this cohort is slightly lower than that reported in comparable U.S. population datasets. Data from the National Longitudinal Study of Adolescent Health (Add Health), collected at around the same time as the Project EAT study (1996-2002), and using a very similar measure, reported a fast food consumption frequency of 2.15 (SE 0.05) times per week at age 16, and 2.48 (SE 0.05) times per week at age 21 [13]. Meanwhile, recent data from the U.S. National Health and Nutrition Examination Survey (2013-2016), collected using a 24-h dietary recall, reported that $45 \%$ of young adults (aged 20-39) reported consuming fast food on a given day [9], with an overall decrease in fast food consumption with age among U.S adults [9].
There are very limited data on changes in diet and eating behaviours across early adulthood life transitions, as reported in our recent systematic reviews [20, 21], and we have found no other studies that systematically looked at changes in fast food intake across life transitions. Our finding of a relative decrease in fast food intake on leaving the parental home may initially seem counterintuitive. Previous research has suggested that consumption of meals with the family is associated with higher diet quality in adolescence [30], and we have previously shown that leaving the parental home is associated with a decrease in fruit and vegetable consumption in early adulthood in a Norwegian cohort [18]. One explanation for the decrease in fast food intake seen in the current study on leaving the parental home could be a decrease in financial resources in this group. Studies of U.S. adolescents and young adults has shown high price sensitivity to fast food, with an increase in price associated with a decrease in frequency of fast food consumption $[31,32]$. Young adults may therefore reduce, or limit, their increase in fast food intake when they are no longer supported financially by their family. This explanation would fit with our finding that this decrease is seen primarily at younger ages, and the association reduces in 


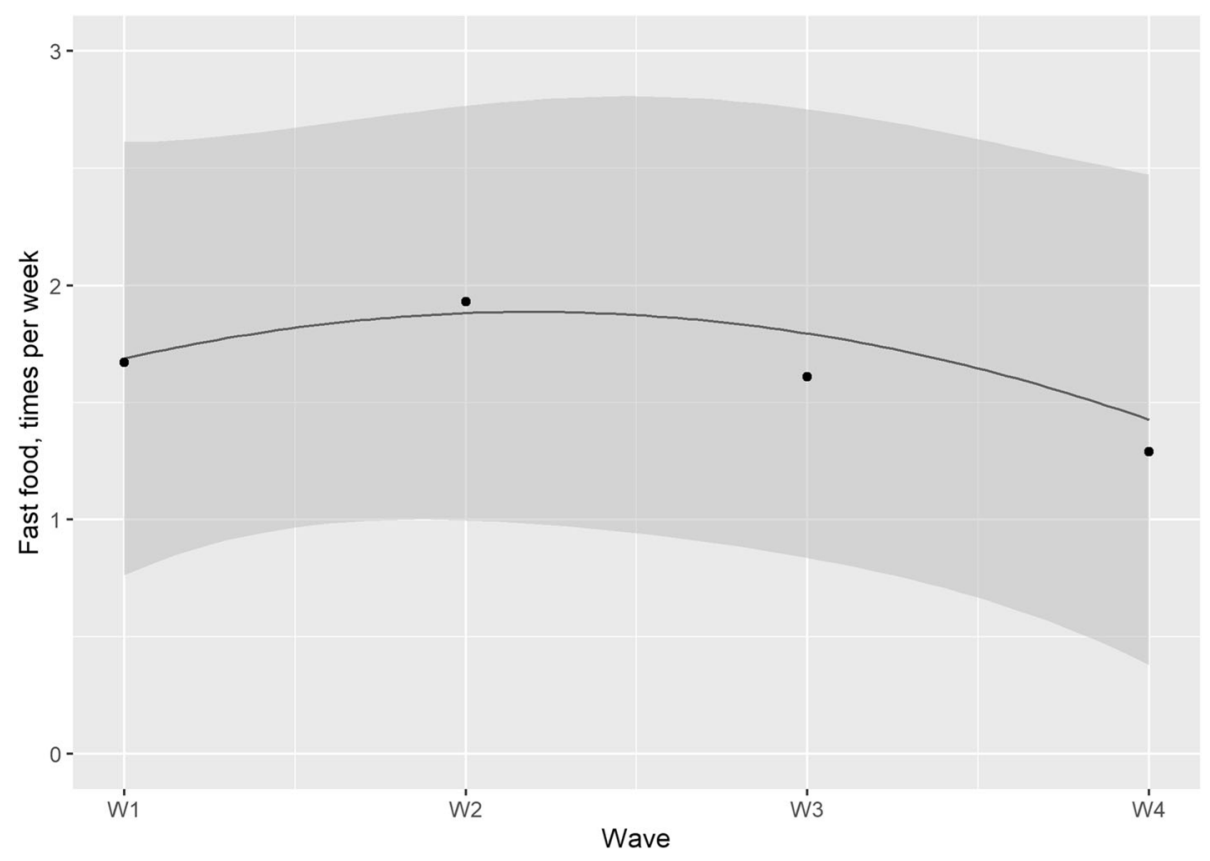

Change in fast food intake with age. The points show mean fast food intake at each age, the line shows the modelled growth curve representing the underlying mean trajectory over time. The shaded area represents the standard error around the mean growth curve

Fig. 2 Change in fast food intake with age

later waves of this study. Another factor to consider is the environment to which young people are moving. A portion of our participants will be moving to live on college and university campuses, where institutional meal provision arrangements may reduce the need for further food purchase from fast food restaurants. Previous research in Project EAT has shown that young women living on campus consumed fast food less frequently than those living with parents or in rented accommodation, after adjusting for sociodemographic covariates [33]. Others have further suggested that those who live with their families may use fast food restaurants as a social space to spend time with friends outside the parental home $[34,35]$, so this need may diminish following a move to living independently.

We did not see any changes in fast food intake on the transition out of education. A previous study reported increases in confectionery and sugar-sweetened beverage consumption over this transition [18], but the mechanisms may be different for fast food intake. We found that starting full-time employment was associated with an increase in fast food intake. This would fit with an economic explanation of changes in fast food purchasing, since on beginning employment participants would be expected to have greater financial resources. Another

Table 3 Association of transtions with additional change in fast food intake, beyond the underlying trajectory, among participants in the Project EAT study with two or more waves of survey data $(n=2902)$

\begin{tabular}{|c|c|c|c|c|}
\hline \multirow[b]{3}{*}{ Transition } & \multicolumn{4}{|c|}{ Change in fast food intake, times per week, across transitions, $\beta$ ( $p$-value) } \\
\hline & \multirow{2}{*}{$\begin{array}{l}\text { Model 1: Transitions across all waves } \\
\text { All waves }\end{array}$} & \multicolumn{3}{|c|}{ Model 2: Transitions between pairs of waves } \\
\hline & & Waves 1-2 & Waves 2-3 & Waves 3-4 \\
\hline Leaving the parental home & $-0.17(0.004)$ & $-0.25(<0.001)$ & $-0.15(0.03)$ & $0.01(0.91)$ \\
\hline Leaving full-time education & $-0.01(0.90)$ & $0.04(0.64)$ & $-0.05(0.48)$ & $-0.07(0.54)$ \\
\hline Beginning full-time employment & $0.16(0.004)$ & $0.22(0.001)$ & $0.11(0.10)$ & $0.20(0.06)$ \\
\hline Beginning cohabitation & $-0.16(0.007)$ & $-0.05(0.60)$ & $-0.17(0.01)$ & $-0.20(0.02)$ \\
\hline Becoming a parent & $0.16(0.004)$ & $0.19(0.05)$ & $0.15(0.05)$ & $0.13(0.08)$ \\
\hline
\end{tabular}

Model 1 constrains associations to be the same across all waves, while Model 2 allows associations to vary over time. In other respects these models are identical. Models are adjusted for time-invariant covariates, the underlying growth curve, and mutually adjusted for the other transitions (see Fig. 1). Mean age at each wave: wave 1: $14.9 y(S D=1.6)$, wave $2: 19.4 y(S D=1.7)$, wave 3: $25.3 y(S D=1.6)$ and wave 4: $31.1 \mathrm{y}(S D=1.6)$ 
contributing factor could be a decrease in time available for food preparation as a result of an increase in time spent working and commuting when entering full-time employment.

Qualitative studies have suggested that many changes in eating behaviours and diet can occur due to new partnerships, where those newly cohabiting/married typically negotiate and compromise to allow them to share food purchasing and preparation and enjoy meals together $[36,37]$. Our finding of a decrease in fast food intake as individuals start cohabitation may reflect a change to more home cooking with a partner. Married participants of the Coronary Artery Risk Development in Young Adults (CARDIA) study were reported to live in neighbourhoods with lower poverty and lower fast food restaurant density [38], therefore the change in consumption may also reflect a change in physical living environments and fast food availability. Similar to the findings reported here, an Australian longitudinal study reported a greater decrease in fat and saturated fat consumption from age 18 to 25 years among men (but not women) living with a partner at 25 years, compared to those without a partner [39].

Finally, we found that fast food intake increased among those who became a parent for the first time. This is consistent with the use of fast food for time-saving and convenience [34]. This finding is also consistent with analysis of the Australian Longitudinal Study on Women's Health, where starting a family was associated with an increase in consumption of high-fat and sugar diets, as well as an increase in total energy intake [40]. Data from the CARDIA study reported no difference in change in fast food intake over a 7 year period between those who became parents and non-parents [41]. However, the CARDIA cohort were older than the Project EAT cohort, aged 25y at baseline, and this observation is therefore in agreement with the decreasing strength of association across later waves that we find in these analyses.

\section{Strengths and limitations of the study}

This is the first analysis, to our knowledge, to investigate longitudinal associations between multiple life transitions and changes in fast food intake across early adulthood. Strengths of this analysis include the use of data from the longitudinal Project EAT cohort, which allowed us to study changes in fast food intake over a 15 year period including early adulthood, a notoriously difficult period of life to study [42]. Data on a wide range of social measures, including living arrangements, educational and employment status, and children, allowed us to assess associations between fast food intake and individual transitions independently, controlling for co-occurrence of other transitions.
One limitation of this dataset was the simplicity of the fast food measure. Intake of fast food was based on only a single question on frequency of consumption, with a categorical response option, which although it is similar to measures used elsewhere, has not been validated against other dietary assessment methods [13]. In addition, respondents were asked to report on consumption during the 'last week' which may not have been a typical week for all participants. These limitations may lead to greater measurement error than would be expected from a more detailed questionnaire. However, a strength is that the same question was repeated across all waves, so it is likely that any response bias would be consistent across waves and would not affect our analysis of changes in intake. We have previously reported secular trends in adolescent fast food intake in the Minneapolis/St. Paul population, which suggest an overall decrease in fast food intake over a similar time frame to this study [43]. These secular trends may have affected the shape of our underlying fast food trajectory, as study participants will have been responding to macrolevel societal and environmental changes as well as individual developmental changes with age. However, we would not expect these secular trends to affect the associations seen between life transitions and fast food intake since our model accounts for the underlying fast food trajectory. A further limitation is that data were collected at only four time points, which were each 5 years apart. As such we were not able to assess the immediate impact of a transition, but only the longer-term impact of a transition which may have occurred at any time over the last 5 years. Because of this limitation, and the low number of data points available, we did not assess whether a transition resulted in a change in the slope of fast food intake, only whether a step change in fast food intake was seen between one wave and the next. As with all observational cohort studies there is a trade-off between a desire for detailed data collection on one aspect of the study, interest in a wide range of social and behavioural measures, and the level of data collection burden that participants can be expected to tolerate. Nevertheless, the ability of this data to show associations between transitions and changes in intake, despite the expected noise in the outcome variable, indicates the strength of these findings. Further research on changes in more detailed measures of diet across these transitions will be able to confirm or refute these findings. Given that this cohort were recruited from a metropolitan area of Minnesota, it would also be of interest to investigate in future analyses whether the impact of these life transitions is the same in other populations, as well as differences between different population groups, for example whether associations differ by gender or socioeconomic status. 


\section{Conclusions}

Our analyses find that two of the five life transitions of early adulthood, beginning full-time employment and becoming a parent, are associated with increases in fast food intake. The strongest associations were seen between waves 1 and 2 (mean age 15 to 19 years), when each of these transitions was associated with an average increase in fast food intake of around 0.2 times per week, in addition to the underlying age-related increase of a similar magnitude over this period. Our findings suggest that public health policy or interventions designed to reduce fast food intake in young adults may benefit from particular focus on those beginning fulltime employment and becoming a parent, to ameliorate the impact of these transitions. Development of interventions in collaboration with employers recruiting young workers or parent education programs for young parents may facilitate delivery of interventions to the high risk groups identified in this study.

\section{Supplementary information}

Supplementary information accompanies this paper at https://doi.org/10. 1186/s12966-020-01024-4.

Additional file 1 : Table S1. Phi coefficients for associations between pairs of transitions. Table S2. Model fit statistics for tested growth models. Table S3. Association of time-invariant covariates with latent growth factors in the final model.

\section{Abbreviations}

Add Health: National Longitudinal Study of Adolescent Health; AIC: Akaike information criterion; BIC: Bayesian Information Criterion; CARDIA: Coronary artery risk development in young adults study; CFI: Comparative fit index; ICC: Intraclass correlation coefficient; MLR: Maximum likelihood estimator with robust standard errors; Project EAT: Project eating and activity in teens and young adults; RMSEA: Root mean square error of approximation; SE: Standard error; SES: Socioeconomic status; SRMR: Standardized root mean square residual; U.S.: The United States of America

\section{Acknowledgements}

The authors would like to thank all participants who contributed data to the Project EAT study, as well as everyone who assisted with the data collection.

\section{Authors' contributions}

DNS is principal investigator of the Project EAT study, NL is the Project EAT study project director and managed acquisition of data, EW designed the analyses and drafted the manuscript, MRW conducted the analyses, JS advised on statistical aspects of the study. All authors commented on the analysis plan, contributed to the interpretation of results and critically reviewed the final manuscript. The author(s) read and approved the final manuscript.

\section{Funding}

Data collection for the study was supported by grant number R01HL116892 from the National Heart, Lung, and Blood Institute. MW was supported by the National Institute of Diabetes and Digestive and Kidney Diseases, grant number T32DK083250 and DNS was supported by grant number R35HL139853 from the National Heart, Lung, and Blood Institute. The content is solely the responsibility of the authors and does not necessarily represent the official views of the National Institutes of Health. Data analysis was supported by the Centre for Diet and Activity Research (CEDAR), a UKCRC Public Health Research Centre of Excellence. Funding from the British Heart Foundation, Department of Health, Economic and Social
Research Council, Medical Research Council, and the Wellcome Trust, under the auspices of the UK Clinical Research Collaboration, is gratefully acknowledged (087636/Z/08/Z; ES/G007462/1; MR/K023187/1; RES-590-280002). EvS and EW are supported by the Medical Research Council (MC_UU_12015/7, MR/T010576/1). No funders had any involvement in the design of the study, the collection, analysis, and interpretation of data, or in writing the manuscript.

\section{Availability of data and materials}

The datasets generated and/or analysed during the current study are not publicly available but are available from the senior author (DNS) on reasonable request.

\section{Ethics approval and consent to participate}

The University of Minnesota's Institutional Review Board Human Subjects Committee approved all protocols (1207S17861). Parental consent and participant assent obtained at wave 1 and participant consent obtained at each of the subsequent waves.

\section{Consent for publication}

Not applicable.

\section{Competing interests}

The authors declare that they have no competing interests.

\section{Author details}

${ }^{1}$ MRC Epidemiology Unit, University of Cambridge, Cambridge, UK. ${ }^{2}$ Division of Epidemiology and Community Health, School of Public Health, University of Minnesota, Minneapolis, USA. ${ }^{3}$ Department of Psychiatry, University of Cambridge, Cambridge, UK. ${ }^{4}$ Department of Kinanthropology, Charles University in Prague, Prague, Czech Republic.

Received: 13 July 2020 Accepted: 14 September 2020 Published online: 09 October 2020

\section{References}

1. Johnson W, Li L, Kuh D, Hardy R. How Has the Age-Related Process of Overweight or Obesity Development Changed over Time? Co-ordinated Analyses of Individual Participant Data from Five United Kingdom Birth Cohorts. Plos Med. 2015;12:e1001828.

2. Lipsky LM, Nansel TR, Haynie DL, Liu D, Li K, Pratt CA, et al. Diet quality of US adolescents during the transition to adulthood: changes and predictors. Am J Clin Nutr. 2017;105:1424-32.

3. Craigie AM, Lake AA, Kelly SA, Adamson AJ, Mathers JC. Tracking of obesityrelated behaviours from childhood to adulthood: A systematic review. Maturitas. 2011;70:266-84.

4. Miller PE, Cross AJ, Subar AF, Krebs-Smith SM, Park Y, Powell-Wiley T, et al. Comparison of 4 established DASH diet indexes: examining associations of index scores and colorectal cancer. Am J Clin Nutr. 2013;98:794-803.

5. Liese AD, Krebs-Smith SM, Subar AF, George SM, Harmon BE, Neuhouser $M L$, et al. The dietary patterns methods project: synthesis of findings across cohorts and relevance to dietary guidance. J Nutr. 2015;145:393-402.

6. Verplanken B, Roy D. Empowering interventions to promote sustainable lifestyles: testing the habit discontinuity hypothesis in a field experiment. J Environ Psychol. 2016:45:127-34.

7. Guthrie JF, Lin BH, Frazao E. Role of food prepared away from home in the American diet, 1977-78 versus 1994-96: Changes and consequences. J Nutr Educ Behav. 2002;34:140-50.

8. Nielsen S. Trends in Food Locations and Sources among Adolescents and Young Adults. Prev Med. 2002;35:107-13.

9. Fryar CD, Hughes JP, Herrick KA, Ahluwalia N. Fast Food Consumption Among Adults in the United States, 2013-2016. NCHS Data Brief, no 322. Hyattsville; 2018. Available from: https://www.cdc.gov/nchs/products/ databriefs/db322.htm. [cited 2020 Sep 28].

10. Food Standards Agency. Food and You - Wave Four. 2018. Available from: https://www.food.gov.uk/research/food-and-you/food-and-you-wave-four. [cited 2020 Aug 26].

11. Larson N, Neumark-Sztainer D, Laska MN, Story M. Young adults and eating away from home: associations with dietary intake patterns and weight status differ by choice of restaurant. J Am Diet Assoc. 2011;111:1696-703. 
12. Pereira MA, Kartashov Al, Ebbeling CB, Van Horn L, Slattery ML, Jacobs PDR, et al. Fast-food habits, weight gain, and insulin resistance (the CARDIA study): 15-year prospective analysis. Lancet. 2005;365:36-42.

13. Niemeier HM, Raynor HA, Lloyd-Richardson EE, Rogers ML, Wing RR. Fast food consumption and breakfast skipping: predictors of weight gain from adolescence to adulthood in a nationally representative sample. J Adolesc Health. 2006;39:842-9.

14. Neumark-Sztainer D, Wall MM, Chen C, Larson NI, Christoph MJ, Sherwood NE. Eating, Activity, and Weight-related Problems From Adolescence to Adulthood. Am J Prev Med. 2018;55:133-41 [cited 2019 Apr 15].

15. Larson NI, Neumark-Sztainer DR, Story MT, Wall MM, Harnack LJ, Eisenberg ME. Fast food intake: longitudinal trends during the transition to young adulthood and correlates of intake. J Adolesc Heal. 2008;43:79-86.

16. Arnett JJ. Emerging adulthood: a theory of development from the late teens through the twenties. Am Psychol. 2000;55:469-80.

17. Dahlgren G, Whitehead M. Policies and strategies to promote social equity in health. Stockholm; 1991. Available from: https://core.ac.uk/download/ pdf/6472456.pdf. [cited 2020 Sep 28].

18. Winpenny EM, van Sluijs EMF, White M, Klepp K-I, Wold B, Lien N. Changes in diet through adolescence and early adulthood: longitudinal trajectories and association with key life transitions. Int J Behav Nutr Phys Act. 2018;15:86.

19. Skogbrott Birkeland M, Leversen I, Torsheim T, Wold B. Pathways to adulthood and their precursors and outcomes. Scand J Psychol. 2014:55:26-32.

20. Corder K, Winpenny EM, Foubister C, Guagliano JM, Hartwig XM, Love R, et al. Becoming a parent: a systematic review and meta-analysis of changes in BMI, diet, and physical activity. Obes Rev. 2020;21:e12959.

21. Winpenny EM, Smith M, Penney T, Foubister C, Guagliano JM, Love R, et al. Changes in physical activity, diet and body weight across the education and employment transitions of early adulthood: A systematic review and meta-analysis. Obes Rev. 2020;21:e12962.

22. Neumark-Sztainer D, Story M, Hannan PJ, Croll J. Overweight status and eating patterns among adolescents: where do youths stand in comparison with the healthy people 2010 objectives? Am J Public Health. 2002;92:844-51.

23. Neumark-Sztainer D, Croll J, Story M, Hannan PJ, French SA, Perry C. Ethnic/ racial differences in weight-related concerns and behaviors among adolescent girls and boys: findings from project EAT. J Psychosom Res. 2002;53:963-74.

24. Larson N, Chen Y, Wall M, Winkler MR, Goldschmidt AB, Neumark-Sztainer D. Personal, behavioral, and environmental predictors of healthy weight maintenance during the transition to adulthood. Prev Med (Baltim). 2018; 113:80-90.

25. U.S. Department of Education National Center for Education Statistics. 201516 National Postsecondary Student Aid Study. Dig. Educ. Stat. Table 311.32. Number Percent. Grad. students Enroll. distance Educ. or online classes degree programs, by Sel. Charact. 2018. Available from: https://nces.ed.gov/ programs/digest/d18/tables/dt18_311.32.asp. [cited 2020 May 7].

26. U.S. Internal Revenue Service. Identifying Full-time Employees. 2020. Available from: https://www.irs.gov/affordable-care-act/employers/ identifying-full-time-employees\#: :text=Definition of Full-Time Employee,hours of service per month. [cited 2020 Jul 3].

27. Haines J, Neumark-Sztainer D, Wall M, Story M. Personal, behavioral, and environmental risk and protective factors for adolescent overweight Obesity (Silver Spring). 2007;15:2748-60.

28. Sherwood NE, Wall M, Neumark-Sztainer D, Story M. Effect of socioeconomic status on weight change patterns in adolescents. Prev Chronic Dis. 2009;6:A19.

29. Curran PJ, Muthén BO, Harford TC. The influence of changes in marital status on developmental trajectories of alcohol use in young adults. J Stud Alcohol. 1998;59:647-58.

30. Larson NI, Neumark-Sztainer D, Hannan PJ, Story M. Family meals during adolescence are associated with higher diet quality and healthful meal patterns during young adulthood. J Am Diet Assoc. 2007;107:1502-10.

31. Gordon-Larsen P, Guilkey DK, Popkin BM. An economic analysis of community-level fast food prices and individual-level fast food intake: a longitudinal study. Health Place. 2011;17:1235-41.

32. Deliens T, Deforche B, Annemans L, De Bourdeaudhuij I, Clarys P. Effectiveness of Pricing Strategies on French Fries and Fruit Purchases among University Students: Results from an On-Campus Restaurant Experiment. Plos One. 2016;11:e0165298.
33. Nelson Laska M, Larson NI, Neumark-Sztainer D, Story M. Dietary patterns and home food availability during emerging adulthood: do they differ by living situation? Public Health Nutr. 2010;13:222-8.

34. Rydell SA, Harnack $L$, Oakes JM, Story M, Jeffery RW, French SA. Why eat at fast-food restaurants: reported reasons among frequent consumers. J Am Diet Assoc. 2008;108:2066-70.

35. Alam A. The Chicken Shop. UCL Centre for Gender and Global Health blog. 2020. Available from: http://www.ighgc.org/blogpost/the-chicken-shop . [cited 2020 Mar 24].

36. Bove CF, Sobal J, Rauschenbach BS. Food choices among newly married couples: convergence, conflict, individualism, and projects. Appetite. 2003; 40:25-41.

37. Kemmer D, Anderson AS, Marshall DW. Living together and eating together: changes in food choice and eating habits during the transition from single to married/cohabiting. Sociol Rev. 1998;46:49-72.

38. Boone-Heinonen J, Howard AG, Meyer K, Lewis CE, Kiefe Cl, Laroche HH, et al. Marriage and parenthood in relation to obesogenic neighborhood trajectories: The CARDIA study. Heal Place. 2015;34:229-40.

39. Burke V, Beilin LJ, Dunbar D, Kevan M. Changes in health-related behaviours and cardiovascular risk factors in young adults: associations with living with a partner. Prev Med (Baltim). 2004;39:722-30.

40. Elstgeest LEM, Mishra GD, Dobson AJ. Transitions in living arrangements are associated with changes in dietary patterns in young women 123. J Nutr Nutr Epidemiol J Nutr. 2012;142:1561-7.

41. Laroche HH, Wallace RB, Snetselaar L, Hillis SL, Steffen LM. Changes in diet behavior when adults become parents. J Acad Nutr Diet. 2012;112:832-9.

42. Winpenny EM, Penney TL, Corder K, White M, van Sluijs EMF. Change in diet in the period from adolescence to early adulthood: a systematic scoping review of longitudinal studies. Int J Behav Nutr Phys Act. 2017;14:60.

43. Larson N, Hannan PJ, Fulkerson JA, Laska MN, Eisenberg ME, NeumarkSztainer D. Secular trends in fast-food restaurant use among adolescents and maternal caregivers from 1999 to 2010. Am J Public Health. 2014;104: 62-9.

\section{Publisher's Note}

Springer Nature remains neutral with regard to jurisdictional claims in published maps and institutional affiliations.
Ready to submit your research? Choose BMC and benefit from:

- fast, convenient online submission

- thorough peer review by experienced researchers in your field

- rapid publication on acceptance

- support for research data, including large and complex data types

- gold Open Access which fosters wider collaboration and increased citations

- maximum visibility for your research: over $100 \mathrm{M}$ website views per year

At BMC, research is always in progress.

Learn more biomedcentral.com/submissions 